\title{
Cotidiano, cultura e memória:
}

\section{redes e sociabilidades em uma localidade urbana da llha de Santa Catarina}

\author{
Tereza Mara Franzoni
}

\begin{abstract}
A pesquisa tem como objetivo, realizar um levantamento exploratório sobre, as redes de sociabilidade que envolvem grupos e associações de caráter cultural, comunitário e religioso na localidade conhecida como Morro do Quilombo em Florianópolis, realizando também um mapeamento dos eventos e espaços de uso coletivo nesta localidade. A idéia de sociabilidade vem de Georg Simmel (2006), que vê nas reuniões e formas de associação, além das necessidades e interesses específicos, um outro impulso, "uma satisfação de estar justamente socializado, pelo valor da formação da sociedade enquanto tal", que ele chama de "impulso da sociabilidade". Nesta perspectiva, tratar os eventos, as organizações e as formas associativas como espaços de sociabilidade, implica ultrapassar tanto uma visão utilitarista da ação humana, como uma visão determinista da cultura e levar em conta as relações entre cultura e subjetividade. A pesquisa está em andamento, tendo realizado a revisão da literatura disponível sobre o tema da sociabilidade urbana contemporânea e os primeiros contatos com os moradores locais, possíveis entrevistados da pesquisa. É sobre a revisão de literatura que tratamos aqui.
\end{abstract}

Os estudos sobre formas de sociabilidade nos contextos urbanos no Brasil trouxeram, inicialmente, os pressupostos da teoria da modernização (Oliven, 1984), para a qual o clientelismo e o paternalismo, assim como as práticas religiosas e o associativismo, teriam perdurado por conta de um "capitalismo tardio", e da permanência de formas próprias do meio rural. Nos estudos mais recentes, ainda que em muitos casos seja mantida a idéia de uma certa "especificidade da vida urbana", em particular na metrópole (Velho, 1999), novas formas de perceber a sociedade modernacontemporânea têm sido adotadas. Autores como Simmel, foram recuperados para pensar as formas de sociabilidade modernas (Souza e Öelze, 2005), e para tratar da cultura e da comunicação num contexto onde os indivíduos/ sujeitos são fundamentais para a compreensão das "diferenciações" e "descontinuidades" (Velho \& Kuschnir, 2001).

Para Simmel (1989 e 2005b) as idéias de igualdade e liberdade formam a subjetividade do século XIX, a metrópole é a fusão das duas. Para ele, o que define a modernidade é a perda da substância, o que a caracteriza é a transição. Há uma tensão entre o lado nivelador e a individualização, a atitude blasé é a reação a esta tensão (Simmel, 1967). Diferentemente de Weber, Simmel não vê a racionalidade de forma negativa ${ }^{1}$, ao contrário, ela é valorizada como vida do intelecto e, neste sentido, a vida na pólis é pensada como possibilidade da própria filosofia. Velho (1989) propõe uma leitura de Simmel a partir das relações entre sociabilidade e subjetividade, indicando a relação entre o desenvolvimento de culturas subjetivas (termo de Simmel, 2005a) e o exercício de atividades associativa, o que parece bastante frutífero do ponto de vista da pesquisa.

Vivemos um momento onde é necessário, por vezes recriar os conceitos teóricos, como diz Hannerz (1997), porém acreditamos também que é preciso re-vizitar alguns dos autores clássicos. Formulações como as de Clifford (1997), sugerindo pensar a própria constituição dos objetos teóricos a partir da experiência cultural do encontro, assim como as reflexões

1 Para Weber (1994), com o predomínio das idéias individualistas sobre as idéias religiosas perdemos um aspecto importante dado por esta última, um forte amalgama social. Sua visão sobre este fenômeno é bastante negativa. A racionalização do mundo é, para Weber, seu desencantamento e a perda da magia, da religião e da arte. 
de Bhabha (1998) trabalhando as idéias de interstícios, sombra, hibridismo e liminaridade, nos colocam diante de novas possibilidades de compreender as relações contemporâneas. As reflexões iniciais sobre etnicidade são então revisitadas e reinterpretadas a luz das novas questões.

A análise das relações de poder são também consideradas a partir da contribuição de Michel Foucault. Para ele (1995), a nova forma de poder instituída com o Estado moderno, nos coloca diante de um "duplo constrangimento" político, que é "a simultânea individualização e totalização própria às estruturas do poder moderno" (p. 239). Temos aqui, de certa forma, a mesma questão proposta por Simmel (1967), que também caracteriza a modernidade pela tensão entre o lado nivelador e a individualização ${ }^{2}$. Esta é a "malha de relações" que constituem a sociabilidade contemporânea.

A proposta é identificar estas formas e seus significados para os moradores locais. Esperase que a reflexão sobre estas formas possam contribuir para uma melhor compreensão das formas de convivência e dos valores que fortalecem as relações de respeito e aproximação, de troca e de inclusão, assim como daquelas que desencadeiam as tensões e a exclusão de parte de uma determinada população.

Ainda que de forma bastante parcial é possível adiantar algumas informações sobre a pesquisa. A literatura acadêmica sobre Morro do Quilombo é bastante limitada, restringindo-se a trabalhos de graduação, projetos de extensão e partes de levantamentos sobre áreas periféricas do Município. No caso da imprensa local, onde também é possível encontrar algumas referências, a imagem desta localidade esta geralmente vinculada a questão ambiental. Fala-se sobre o manancial de água que fica no local, sobre o desmatamento da região e entorno, sobre problemas de deslizamentos de terras, etc. Outro tema recorrente é o da violência urbana, não raramente identificando a localidade com refúgio de criminosos.

Outras referências são encontradas a partir das pesquisas sobre o entorno mais amplo, ou seja, o bairro do Itacorubi. Neste caso, grande parte das pesquisas consultadas também privilegiam aspectos ambientais. Muitas destas referências, trazem dados sócio econômicos e históricos interessantes sobre a região, no entanto, apontam para a análise da região enquanto Bacia do Itacorubi, ou seja, a partir de uma referência que tem como foco a questão ambiental, em especial a hidrografia e os impactos da ocupação humana sobre ela.

Alguns trabalhos na área social, tratando de questões relacionadas a educação, saúde e fluxos migratórios também foram encontrados, porém em pequena quantidade e revelando estudos geralmente limitados a micro regiões no interior do bairro.

Sobre algumas das conversas com moradores locais e as observações iniciadas é possível comentar, de forma ainda não conclusiva, algumas questões. A localidade dispõe de poucas áreas de uso comum. Sendo as vias públicas de acesso de automóveis o espaço privilegiado de muitas das brincadeiras infantis, encontros e conversas. A região onde localiza-se a represa do Morro do Quilombo (manancial de água que abastece as partes médias e altas do bairro do Itacorubi) é outra região privilegiada. Devido a grande área arborizada no entorno da represa, apesar da proibição de acesso por parte das instituições responsáveis, esta região conta com várias visitas de membros da comunidade para passeios, brincadeiras, namoros e outras atividades. Além desta região, ás áreas mais elevadas que ainda contam com vegetação, também são de uso freqüente dos moradores, funcionando ainda alguns dos antigos caminhos que ligavam esta região com localidades da Lagoa da Conceição. Existem áreas menores, possivelmente destinadas a antigas pastagens que são utilizadas para jogar bola, brincar de "pandorga" ou "pipa", entre outras coisas.

Existem também locais construídos ou disponibilizados por iniciativa de grupos ou associações de moradores da própria comunidade. Este é o caso das construções e casas destinadas aos cultos, encontros e reuniões de grupos de várias religiões. Algumas Instituições próximas da localidade como EPAGRI, UDESC, Centro de Ciências Agrárias da UFSC, Conselho Comunitário do Itacorubi, Escolas públicas, entre outros, também são utilizados como uma espécie de extensão da comunidade para reuniões, cursos e atividades geralmente de caráter organizativo e associativo.

Alguns espaços de caráter privado como os bares, são também locais de convívio e reuniões. Servindo para jogar dominó, cartas e outros, além das conversas e bebidas, funcionam também como importantes locais de circulação de notícias e informações (avisos de emprego, recados para os freqüentadores, debates sobre 
acontecimentos recentes, etc). No entanto, áreas destinadas ou construídas para o convívio e o lazer pelo poder público, praticamente inexistem. As exceções são os parques e praças construídos nas regiões mais baixas, que já não são consideradas pelos moradores parte do Morro do Quilombo, ainda que muitas vezes utilizados pela comunidade.

Nas poucas conversas que tive é comum a fala sobre a ausência de espaços de convívio, assim como sobre a diminuição das áreas de lazer, em especial aquelas que se localizam na mata, cursos de água e terrenos baldios. O uso das vias de acesso como espaço de lazer também é apontado por alguns como algo que está desaparecendo. Neste último caso, a justificativa dada, é a do aumento da violência. A rua já não é segura, dizem.

Sobre os eventos festivos, a maior parte dos depoimentos até o momento, citou eventos familiares e encontro entre amigos, apontando como eventos comuns basicamente eventos religiosos e/ou promovidos pelas escolas locais. Estes também cada vez mais raros e com mais restrições (limitação de convidados externos, bebidas alcoólicas, horário de término, etc). No entanto, como esta é ainda uma fase em andamento na pesquisa, não é possível apontar diferenças significativas entre os vínculos de quem fala e suas opiniões. Alguns dos entrevistados fizeram referências a intervenções pontuais na comunidade como cursos, projetos e grupos de produção e geração de emprego. Estes também apontados como momentos de convívio e socialização. É neste campo que as instituições públicas aparecem como atores significativos na criação de espaços de convívio.

É importante frisar que a pesquisa foi realizada parcialmente, cumprindo apenas algumas de suas etapas. Neste sentido as informações que constam do presente artigo são ainda provisórias. As etapas de realização das entrevistas; observação de eventos; e observação espacial da localidade, foram apenas iniciadas, faltando realizar ainda as etapas de organização dos dados e a redação do relatório final propriamente dito.

\section{Referências Bibliográficas}

BHABHA,HomiK.1998. Interrogandoaidentidade: Frantz Fanon e a prerrogativa pós colonial. In: O local da cultura. Belo Horizonte, Ed. UFMG.

CLIFFORD, James. 1997. Traveling Cultures. In: Routes: travel and translation in the late twentieth century. Cambridge: Harvard University Press.
FOUCAULT, Michel. 1995. O sujeito e o poder. In: DRYFUS, Hubert L. \& RABINOW, Paul. Uma trajetória filosófica: Para além do estruturalismo e da hermenêutica. São Paulo, Forense Universitária.

HANNERZ, Ulf. 1997. Fluxos, fronteiras, híbridos: palavras chaves da antropologia transnacional. In: Mana 3/1. Museu Nacional. Rio de Janeiro, abril de 1997.

OLIVEN, Ruben. 1984. Urbanização e Mudança Social no Brasil. Petrópolis, Vozes.

SIMMEL, Georg. 1967. A metrópole e a vida mental. In: VELHO, Otávio G. O Fenômeno Urbano. Rio de Janeiro: Zahar.

SIMMEL, Georg. 1989. Philosophie de la Modernité. La femme, la ville, l'individualisme. Paris, Payot.

SIMMEL, Georg. 2005a. A divisão do trabalho como causa da diferenciação da cultura subjetiva e objetiva. In: SOUZA, Jessé \& ÖELZE, Berthold. 2005. Simmel e a modernidade. 2a. ed. Brasília: UNB.

SIMMEL, Georg. 2005b. O indivíduoea liberdade. In: SOUZA, Jessé \& ÖELZE, Berthold. 2005. Simmel e a modernidade. 2a. ed. Brasília: UNB.

SIMMEL, Georg. 2006. Questões fundamentais de sociologia: indivíduo e sociedade. Rio de Janeiro: Jorge Zahar Ed.

SOUZA, Jessé \& ÖELZE, Berthold. 2005. Simmel e a modernidade. 2a. ed. Brasília: UNB.

VELHO, Gilberto \& KUSCHNIR, Karina. 2001. (Orgs). Mediação, Cultura e Política. Rio de Janeiro: Aeroplano.

VELHO, Gilberto. 1989. (Org). Subjetividade e sociedade. Uma experiência de geração. 2a ed. Rio de Janeiro: Jorge Zahar Editor.

VELHO, Gilberto. 1999. (Org). Antropologia Urbana. Cultura e Sociedade no Brasil e em Portugal. Rio de Janeiro: Jorge Zahar Editor.

VELHO, Gilberto. 2005. Unidade e fragmentação em sociedades complexas. In: SOUZA, Jessé \&

WEBER, Max. 1994. Sociologia da religião In: Economia e Sociedade: fundamentos da sociologia compreensiva. 3a ed. Brasília: Universidade de Brasília. 